\title{
$\nabla$
}

\section{Dermatoses bolhosas auto-imunes}

\author{
Autoimmune bullous dermatoses
}

\author{
Paulo R. Cunha ${ }^{1}$
}

\author{
Silvia Regina C. S. Barraviera ${ }^{2}$
}

\begin{abstract}
Resumo: Dermatoses bolhosas autoimunes são doenças cuja manifestação cutânea primária e fundamental consiste em vesículas e bolhas. Classificam-se conforme a localização da bolha, em intraepidérmica e subepidérmica.

Os pacientes produzem autoanticorpos contra estruturas específicas da pele detectáveis por técnicas de imunofluorescência, immunobloting e Elisa. Os recentes avanços da biologia molecular e celular têm permitido conhecer esses autoantígenos, contra os quais os pacientes se sensibilizam e que estão localizados na epiderme ou na junção dermoepidérmica. São doenças de baixa incidência, porém de elevada morbidade e por vezes letais. O objetivo deste trabalho é revisar e descrever os progressos nos conhecimentos de quatro doenças vésico-bolhosas autoimunes: pênfigo foliáceo endêmico (fogo selvagem), pênfigo vulgar, penfigóide bolhoso e dermatite herpetiforme.

Palavras-chave: Alergia e imunologia; Dermatite herpetiforme; Dermatopatias vesiculobolhosas; Penfigo; Penfigóide bolhoso
\end{abstract}

\begin{abstract}
Abstract: Autoimmune bullous dermatoses are diseases in which blisters and vesicles are the primary and fundamental types of skin lesion. Their classification is based on the location of the blister: intraepidermal and subepidermal.

Patients produce autoantibodies against self-specific structures of the skin detectable by immunofluorescence techniques, immunoblotting and ELISA. Recent advances in molecular and cellular biology have brought to knowledge these self-antigens, against which patients are sensitized, and which are found in epidermis or in the dermo-epidermal junction. These are low incidence, but high morbidity diseases that may be fatal. The aim of this article is to review and describe the progress of four autoimmune vesiculobullous disorders: endemic pemphigus foliaceous (wild fire), pemphigus vulgaris, bullous pemphigoid and dermatitis herpetiformis.

Keyword: Allergy and immunology; Bullous pemphigoid; Dermatitis herpetiformis; Pemphigus; Skin diseases vesiculobullous
\end{abstract}

\section{FOGO SELVAGEM INTRODUÇÃO}

Fogo selvagem (FS), também conhecido como pênfigo foliáceo endêmico (PFE), é doença bolhosa autoimune da pele, endêmica no Brasil. Caracterizase, histologicamente, pela formação de bolhas intraepidérmicas com acantólise. Fogo selvagem e pênfigo foliáceo (PF) de Cazenave têm características clínicas e histológicas comuns e ambos apresentam autoanticorpos da subclasse IgG4, cujo antígeno-alvo é a desmogleína 1, antígeno desmossomal de 160kd.

O FS acomete mais frequentemente crianças, adolescentes e adultos jovens que vivem nas áreas rurais de regióes endêmicas, e é comum a ocorrência

\footnotetext{
Aprovado pelo Conselho Editorial e aceito para publicação em 19.12.2008.

* Trabalho realizado na Faculdade de Medicina de Jundiaí (SP) - Brasil.

Conflito de interesse: Nenhum / Conflict of interest: None

Suporte financeiro: Nenhum / Financial funding: None

Professor titular de dermatologia da Faculdade de Medicina de Jundiaí (FMJ), doutor em dermatologia pela Universidade de São Paulo, professor livre-docente da Faculdade de Medicina da Universidade de São Paulo - São Paulo (SP), Brasil. Pós-doutoramento na New York University - New York (NY), Estados Unidos da América.

Professora-assistente doutora do Departamento de Dermatologia e Radioterapia da Faculdade de Medicina de Botucatu (FMB) - São Paulo (SP), Brasil.

C 2009 by Anais Brasileiros de Dermatologia
} 
de casos familiares, enquanto o PF tem ocorrência universal, em geral sem casos familiares.

\section{HISTÓRICO E EPIDEMIOLOGIA}

O primeiro registro de FS no Brasil é de Paes Leme, em tese apresentada à Faculdade de Medicina do Rio de Janeiro em 1903. ${ }^{1}$ No decorrer da década de 1930, o número de casos de FS aumentou significativamente no Estado de São Paulo. ${ }^{2,3}$ Estudos epidemiológicos mostraram então que a incidência de FS tinha tendência a diminuir, fato relacionado com a melhoria das condições de vida das populações, como foi observado no Estado de São Paulo. ${ }^{4,5}$ Atualmente, os principais focos da doença situam-se nos estados de Goiás, Distrito Federal, Mato Grosso, Mato Grosso do Sul, Minas Gerais, Paraná e São Paulo. ${ }^{6}$ Esses aspectos epidemiológicos sugerem que seja uma doença desencadeada por agente ambiental.

\section{PATOGENIA}

Ao se estudar a etiologia do FS, é inevitável considerar três fatores, o imunológico, o genético e o ambiental. FS é doença autoimune de causa desconhecida, provocada por autoanticorpos patogênicos antiepiteliais e responsáveis pelo fenômeno da acantólise. Os autoanticorpos são do tipo imunoglobulina $G(\operatorname{IgG})$, predominando o subtipo IgG4. ${ }^{8}$ Podem ser detectados no soro pela técnica da imunofluorescência indireta (IFI), e seus níveis correlacionam-se diretamente com a extensão e a atividade da doença. ${ }^{5,9-11}$ Assim, o FS é doença autoimune e, ao mesmo tempo, endêmica. O autoantígeno contra o qual os anticorpos antiepiteliais reagem é a desmogleína 1 (Dsg1), molécula, da família das caderinas, que compõe os desmossomos, glicoproteína transmembrânica com uma parte intracelular (endodomínio) e vários domínios extracelulares (ectodomínio - EC). Demonstrou-se que os autoanticorpos do FS em pacientes com doença em atividade reagem contra os ectodomínios EC1 e EC2, que são os domínios extracelulares da Dsg1 mais afastados da membrana celular. $^{6}$

Estudos recentes demonstraram que a prevalência de autoanticorpos contra Dsg1 também é alta entre indivíduos normais morando em áreas endêmicas de fogo selvagem, sugerindo que a produção desses autoanticorpos contra Dsg1 possa ser iniciada pela exposição a um agente desconhecido do ambiente. Ainda não foi identificado nenhum agente infeccioso ou vetor da doença. ${ }^{12}$ Há depósito de anticorpos nas mucosas, mas com ausência de bolhas nos pacientes com FS. ${ }^{13}$

Além do conceito bem definido sobre o papel da imunidade humoral por meio da patogenicidade dos anticorpos da subclasse IgG4 contra a Dsg1, foi demonstrado que os linfócitos T de pacientes com FS mostram respostas proliferativas quando expostos ao ectodomímio da Dsg1 recombinante produzida pelo sistema de expressão do baculovírus, comprovando o envolvimento da imunidade celular no processo. ${ }^{14,15}$

Quanto às possíveis etiologias, é importante o fator genético, havendo forte associação entre FS e quatro HLA DRB1 específicos, que são DRB1 0404, 1402,1406 e $1404 .^{16}$

Simulídeos têm sido implicados como agentes que poderiam precipitar o FS em pessoas imunogeneticamente suscetíveis. Questionários para pacientes de um estudo de caso controle apontam picada de insetos alados como fator de risco (odds ratio: 4,7, $\mathrm{p}<0,001$ ). ${ }^{17}$

Outro agente etiológico potencial aventado para o FS seria o de fatores nutricionais, mas o único estudo realizado ${ }^{18}$ foi inconclusivo.

A possibilidade de ingestão de substâncias tóxicas que poderiam estar presentes na água consumida por indivíduos geneticamente predispostos é uma hipótese ${ }^{19}$ que carece de dados experimentais e estudos mais aprofundados que a comprovem.

Estudos recentes mostram que soros de pacientes com leishmaniose, oncocercose e doença de Chagas, assim como de pessoas normais morando em áreas endêmicas ou de pacientes em remissão, clínica contêm títulos significativos de autoanticorpos antiDsg1 restrito para o domínio EC5 da molécula de Dsg1, sugerindo que antígenos de artrópodes podem ter reação cruzada com Dsg1 epidérmico, desencadeando assim a formação de autoanticorpos em indivíduos expostos a esses artrópodes. Esses achados mostram forte evidência do possível papel de insetos na patogênese do FS. Todas essas doenças são produzidas ou transmitidas por insetos hematófagos. Surge a hipótese de que um componente da saliva do inseto vetor, mais do que o próprio parasita, possa desencadear resposta de anticorpos contra o EC5. Em pessoas com o conhecido HLA de suscetibilidade e moradoras de áreas endêmicas, uma resposta ao domínio EC1-2 pode desenvolver-se subsequentemente por epitope spreading com sinais clínicos do FS associados. ${ }^{20}$

\section{ASPECTOS CLÍNICOS E CLASSIFICAÇÃO}

A lesão cutânea primária e mais característica do FS é bolha superficial que se rompe com facilidade, deixando áreas erosadas, recobertas por escamas finas e crostas. A doença geralmente se inicia pela cabeça, pescoço e regiões seborreicas, evoluindo no sentido crânio-caudal, de forma simétrica. Praticamente todos os pacientes têm lesões na face e/ou no couro cabeludo. O FS não acomete mucosa oral, palmas das mãos e planta dos pés. Na maioria dos pacientes, a doença tem início gradual, com as lesões cutâneas evoluindo durante semanas ou meses. Um 
número menor de pacientes apresenta início mais agudo, com lesões bolhosas extensas que atingem grandes áreas do tegumento.

Clinicamente, o FS evolui segundo duas grandes formas: localizada e generalizada. Na primeira as lesões, em sua maioria, estão limitadas às áreas seborreicas da pele - face, cabeça, pescoço e partes altas do tronco. Em número razoável de pacientes portadores da forma localizada, as lesões ocupam as regiões malares, mostrando imagem bastante semelhante à da 'asa de borboleta' vista no lúpus eritematoso. A maioria dos pacientes da forma localizada permanece sempre com as lesões confinadas a essas áreas, e alguns pacientes portadores dessa forma podem apresentar disseminação das lesões, evoluindo para a forma generalizada. Nesta última, as lesões são numerosas, acometendo mais extensamente tronco e membros, além de face e couro cabeludo. A forma generalizada tem sua expressão máxima na fase eritrodérmica (Figura 1). Há sensação de ardor ou queimação, o que originou o nome "fogo selvagem". Na forma generalizada, complicações como piodermites, dermatofitoses, escabiose e verrugas virais são mais comuns. Disseminação do herpes vírus, levando à erupção variceliforme de Kaposi, foi responsável no passado por muitos óbitos nessa forma da doença e ainda hoje é considerada grave.

A realização de pressão na pele aparentemente normal, próxima à lesão, induz ao descolamento epidérmico (sinal de Nikolsky), que indica atividade da doença.

Para finalizar, os pacientes portadores da forma generalizada podem evoluir em sua fase crônica com lesões do tipo placas verrucosas que têm curso extremamente arrastado.

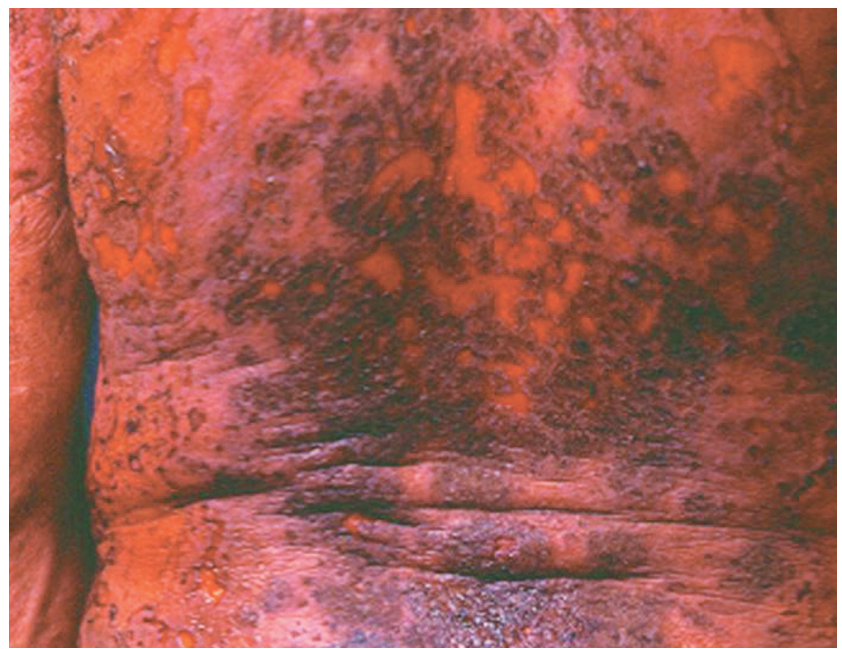

FIGURA 1: Fogo selvagem - Forma generalizada eritrodérmica

\section{DIAGNÓSTICO LABORATORIAL Histopatologia}

A lesão do FS é caracterizada histologicamente pela formação de bolha acantolítica intraepidérmica alta, na região subcórnea ou granulosa (Figura 2). Os sítios dessas bolhas coincidem com a distribuição da Dsg1 na epiderme, que tem maior expressão nas camadas superiores do estrato espinhoso,${ }^{21}$ embora a Dsg1 também esteja presente em menor grau na epiderme profunda, onde a Dsg3 tem sua maior expressão. ${ }^{22}$ As bolhas contêm soro, queratinócitos acantolíticos e, ocasionalmente, neutrófilos e eosinófilos. Apesar de não se observar, à microscopia óptica, a presença de acantólise nas áreas suprabasais, à microscopia eletrônica nota-se que a adesão celular de todas as camadas é afetada em graus variados. ${ }^{23}$

\section{Imunofluorescência}

Imunofluorescência direta (IFD) da pele perilesional de pacientes com FS mostra depósitos de IgG e C3 na superfície dos queratinócitos em todos os casos ativos. ${ }^{24}$ Como em outras formas de pênfigo, um elemento essencial no diagnóstico do FS é a detecção de anticorpos intercelulares (AI) circulantes, classicamente detectados por imunofluorescência indireta (IFI). ${ }^{25}$ Exame de IFI com o soro de pacientes em atividade usando como substrato pele humana normal demonstra, na maioria dos casos de FS, anticorpos IgG circulantes contra a superfície celular dos queratinócitos. A sensibilidade da IFI na detecção de anticorpos do FS é fortemente alterada pelo tipo de substrato utilizado. Cunha ${ }^{26}$ considerou a pele humana normal o substrato mais sensível para a detecção dos autoanticorpos do FS, seguida em ordem decrescente
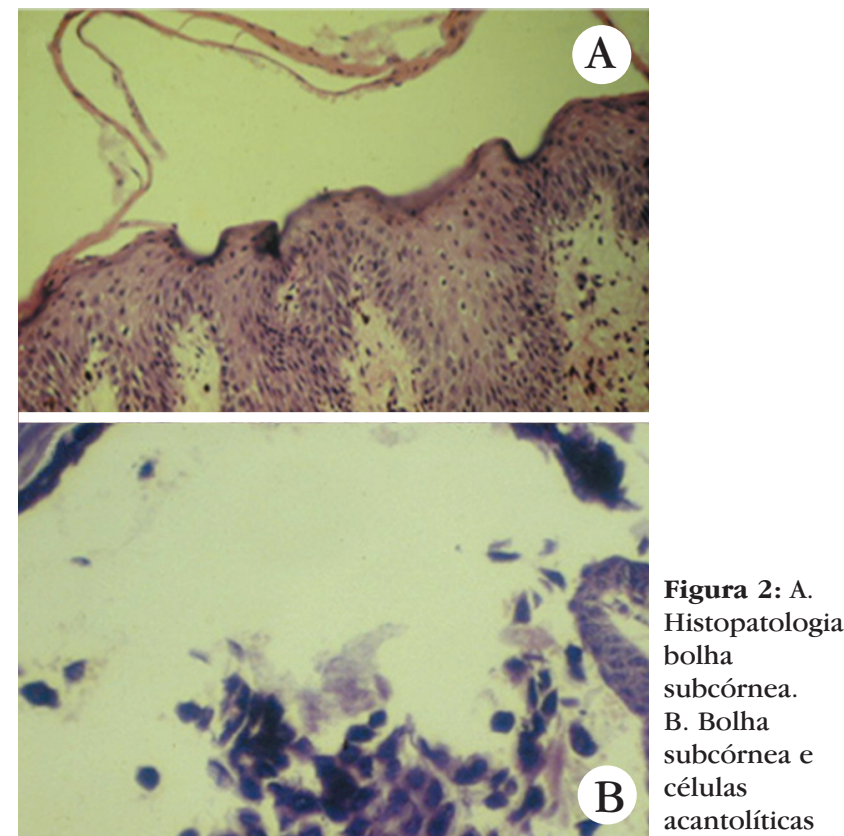
de eficiência por esôfago de porquinho-da-índia, esôfago de macaco e língua bovina. Cunha ${ }^{5}$ verificou que o valor dos títulos de autoanticorpos do FS apresenta correlação com a extensão da doença, sendo os títulos nas formas generalizadas maiores do que nas formas localizadas. Cunha ${ }^{5}$ e Squiquera et $\mathrm{al}^{27}$ através da IFI, utilizando como substrato pele humana normal, realizaram estudo soroepidemiológico em foco endêmico de FS e constataram ausência de autoanticorpos antiepiteliais do FS em familiares consanguíneos, coabitantes e vizinhos dos doentes moradores em áreas endêmicas. Cunha et al. ${ }^{28}$ estudando soros de 23 pacientes com FS por seu padrão de fluorescência contra pele humana normal por IFI, constataram que $83 \%$ dos pacientes reagiram a antígeno(s) intercelular(es) presente(s) na camada superficial da epiderme, em distribuição idêntica àquela do padrão da Dsg1 por anticorpo monocronal AE23. Todavia, os anticorpos em 17\% dos pacientes reagiram a antígeno(s) igualmente expressado(s) em todas as camadas da epiderme, incluindo as camadas profundas, nas quais a Dsg1 não pode ser detectada (Figura 3). Concluíram que os resultados indicam que a resposta dos anticorpos contra a pele de paciente com FS é mais complexa do que se acredita atualmente. Em alguns pacientes, os autoanticorpos são dirigidos a antígenos que diferem da Dsg1 em sua distribuição dentro da epiderme.

\section{Immunoblotting (IB)}

Trata-se de técnica na qual se faz a extração da proteína do epitélio humano normal, após solubilização e separação dessas proteínas por eletroforese $\mathrm{e}$ transferência para papel de nitrocelulose. Realiza-se

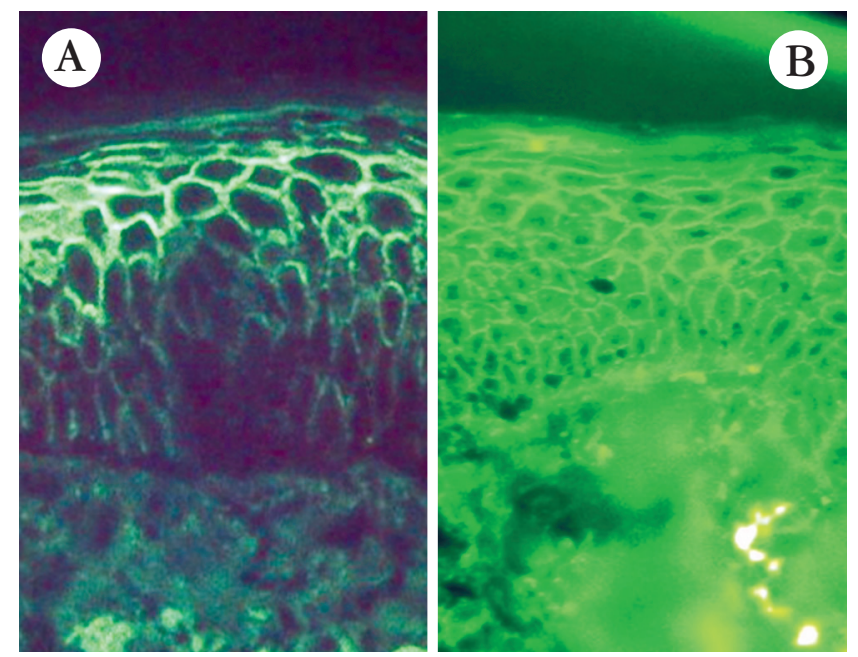

FIGURA 3: A. Padrão de fluorescência nas camadas superficiais da epiderme. B. Em todas as camadas da epiderme incluindo as camadas profundas teste dessas proteínas contra os soros dos doentes. Os anticorpos do pênfigo vulgar (PV) reagem a um antígeno de $130 \mathrm{kD}$ enquanto os do FS o fazem contra antígeno de $160 \mathrm{kD}$ (Figura 4).

Cunha et al., ${ }^{29}$ estudando a sensibilidade dos testes da IFI e do IB para detectar autoanticorpos do FS, constataram que a IFI (71\%) é teste mais sensível do que o IB (28\%) para detecção de anticorpos intercelulares circulantes em pacientes com FS.

\section{Elisa (Enzyme-Linked Immunosorbent Assay)}

$\mathrm{Na}$ atualidade, para o teste de Elisa, existem preparações comerciais de desmogleínas a ser testadas com os soros dos doentes. O teste de Elisa apresenta alta sensibilidade e alta especificidade, e, por ser quantitativo, tem sido indicado como método de eleição para diagnóstico e seguimento dos doentes de FS. Cunha et al., ${ }^{30} \mathrm{em}$ estudo comparativo da sensibilidade da imunofluorescência indireta e do Elisa para a detecção de anticorpos intercelulares no FS, demonstraram que os anticorpos em pacientes com FS foram observados por Elisa (rDsg1) em 91\% dos casos, enquanto a positividade com a imunofluorescência indireta foi de $81 \%$. Nesse mesmo trabalho, os autores concluíram que, embora estudos prévios associem Dsg3 com pênfigo vulgar, $12 \%$ dos pacientes com FS também têm anticorpos contra Dsg3. Concluem sinalizando a não-disponibilidade de teste com $100 \%$ de precisão diferenciando FS do PV.

Anticorpos antiDsg3 foram detectados em 36\% (53/146) de indivíduos normais moradores em uma região endêmica de FS. ${ }^{31}$

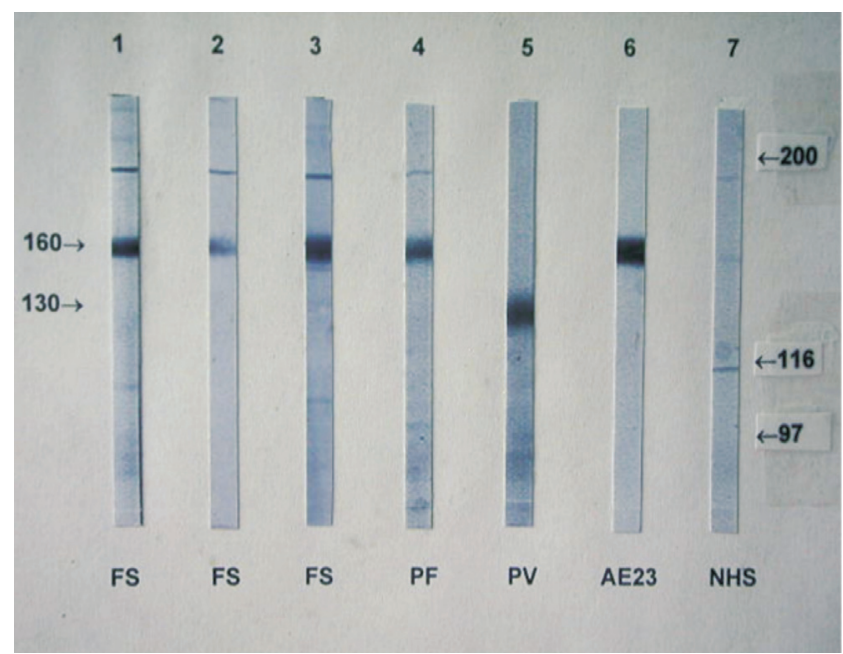

FIgURA 4: Teste de immunoblotting: soro de pacientes com FS reage contra antígeno de $160 \mathrm{kd}$ (Dsg1). Soro de pacientes com fogo selvagem (FS) - linha 1, 2 e 3. Pênfigo foliáceo de Cazenave (PF) - linha 4. Pênfigo vulgar (PV) - linha 5. Dsg1 marcada por anticorpo monoclonal (AE23) - linha 6. Soro humano normal (NHS) - linha 7 


\section{TRATAMENTO}

O tratamento do FS faz-se, principalmente, com prednisona por via oral na dose de um a $2 \mathrm{mg} / \mathrm{kg} / \mathrm{dia}$ (dose máxima de 100 a 120mg dia). A redução do corticóide deve ser iniciada após completa resolução das lesões e o não-surgimento de novas bolhas. A dose é reduzida em $10 \mathrm{mg}$ a cada semana até atingir a dose de $30 \mathrm{mg} /$ dia. Posteriormente, a redução deve ser mais lenta, cinco a $10 \mathrm{mg} / \mathrm{mês}$, atingindo a dose de $10 \mathrm{mg} /$ dia. A retirada ocorre com diminuição de $2,5 \mathrm{mg}$ a cada um ou dois meses, de acordo com a evolução clínica. O tratamento pode ser suspenso após um ano de doses baixas diárias ou em dias alternados, sem surgimento de novas lesões e com a sorologia (IFI) negativa. No período de diminuição da dose do tratamento, podem ser utilizados corticosteróides por via tópica ou mesmo intralesional. Se houver sinais de infecção bacteriana secundária, utilizam-se antibióticos sistêmicos e podem ser recomendados banhos com permanganato de potássio diluído em água na proporção de 1/40.000. Mesmo com o exame parasitológico de fezes negativo, torna-se conveniente a prescrição de medicamentos antiparasitários, principalmente efetivos contra estrongilóides que se podem disseminar com a corticoterapia.

Durante o tratamento do FS, é preciso fazer os exames complementares necessários para garantir o controle absoluto sobre os efeitos indesejáveis da corticoterapia.

Como alternativas terapêuticas, existem os imunossupressores, como a azatioprina e a ciclofosfami$\mathrm{da}$, nas doses usuais de 50 a $100 \mathrm{mg}$ por dia, porém apresentam pouca eficácia no $\mathrm{FS}^{6}{ }^{6}$ Quando não há melhora com corticoterapia sistêmica, pode-se associar micofenolato mofetil na dose de $35-45 \mathrm{mg} / \mathrm{kg} / \mathrm{dia}$ (dose máxima $3 \mathrm{~g} / \mathrm{dia}$ ). Por experiência pessoal do autor, também pode ser utilizado como alternativa terapêutica difosfato de cloroquina na dose de $250 \mathrm{mg}$ por dia, preferencialmente quando as lesões se localizam nas áreas expostas ao sol. $\mathrm{O}$ autor também preconiza a associação de tetraciclina na dose de $2 \mathrm{~g}$ ao dia, nicotinamida, na dose de $1,5 \mathrm{~g}$ ao dia e sulfona $100 \mathrm{mg}$ por dia. Todos esses tratamentos alternativos podem ser utilizados concomitantemente aos corticóides sistêmicos como adjuvantes e poupadores de corticóides. Além dessas orientações, recomenda-se proteção solar, pois a luz ultravioleta pode induzir à formação de bolhas, sendo o sol fator ambiental dos mais importantes no desenvolvimento e piora do FS.

\section{PÊNFIGO VULGAR INTRODUÇÃO}

Pênfigo vulgar (PV) é doença bolhosa intraepidérmica que afeta pele e mucosas, potencialmente fatal. ${ }^{32,33}$ Tem distribuição universal, porém é mais comum entre os judeus. Estudos imunogenéticos demonstram aumentada incidência de HLA-DR4 (em judeus ashkenazi) ou DRw6 (em outros grupos étnicos). ${ }^{3436}$ Cerca de $90 \%$ dos pacientes com PV tem envolvimento oral, e percentual que varia de 50 a $70 \%$ dos doentes inicia o quadro com lesões exulceradas em mucosa oral. ${ }^{32} \mathrm{O}$ PV afeta igualmente ambos os $\operatorname{sexos}^{33}$ e ocorre principalmente em pacientes entre a quarta e a sexta décadas de vida $;{ }^{37}$ todavia, podem ser afetados indivíduos de qualquer idade, incluindo crianças e recém-nascidos de mães com $\mathbf{P V}^{38}$

\section{ETIOPATOGENIA}

Pacientes com PV têm anticorpos IgG4 patogênicos contra Dsg $3{ }^{39,40}$ glicoproteína transmembrânica de $130 \mathrm{kD}$, molécula, pertencente à família das caderinas, que compõe o desmossomo com função de adesão celular da epiderme. Recentes estudos têm mostrado que pacientes portadores de PV com lesão principalmente em membrana mucosa têm apenas anticorpos antiDsg3. Tardiamente, com a progressão da doença envolvendo membrana mucosa e a pele, esses pacientes desenvolvem adicionalmente anticorpos contra Dsg1. Essas recentes observações levam à classificação do PV em PV mucoso e PV mucocutâneo. Na forma mucosa o paciente só apresenta anticorpo antiDsg3 de $130 \mathrm{kD}$ e, mais tardiamente, quando desenvolve lesões também na pele (mucocutâneo), tem anticorpos contra ambos, Dsg1 e Dsg3 ${ }^{41-43}$ A bolha no PV é resultado da perda da coesão dos queratinócitos (acantólise), muito provavelmente como consequência da interferência com a função de adesão da proteína desmossomal, via anticorpos circulantes antidesmogleina. ${ }^{44}$

\section{ASPECTOS CLÍNICOS}

As lesões primárias do PV são bolhas flácidas que surgem em pele normal ou eritematosa. ${ }^{32,33,37,45}$ As bolhas são frágeis e rompem-se rapidamente, formando erosões dolorosas (Figura 5), que sangram com facilidade, e recobertas por crostas hemáticas. A realização de pressão na pele aparentemente normal, próxima à lesão, induz ao descolamento epidérmico (sinal de Nikolsky $)^{45}$ que indica atividade da doença. Se sua superfície for pressionada no sentido vertical, a bolha se estende lateralmente (sinal de Nikolsky II ou sinal de Asboe-Hansen). ${ }^{45}$ As bolhas do PV podem ser localizadas ou generalizadas, e qualquer área da pele pode ser envolvida, embora as áreas de predileção sejam face, axila e cavidade oral, o que se pode dever ao fato de a Dsg3 ter sua maior expressão nessas áreas. ${ }^{46}$ As lesões podem acometer toda a mucosa bucal, mas predominam na mucosa jugal, no palato e nas gengivas. O PV pode apresentar-se como gengivite descamativa. As lesões orais em fase avançada difi- 


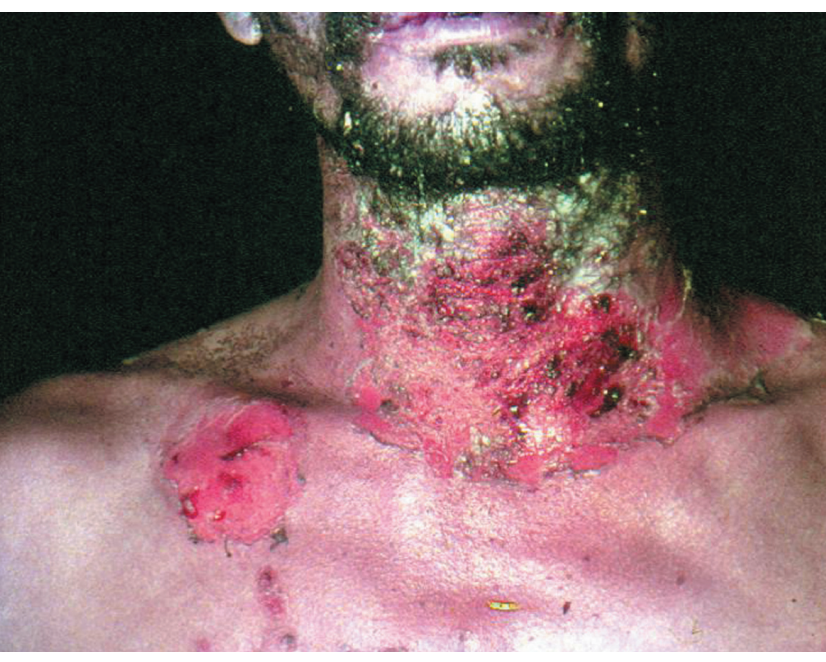

FIGURA 5: Pênfigo vulgar: bolhas rotas, formação de erosões

cultam a alimentação, com comprometimento do estado nutricional. Pode acometer mucosa conjuntival, nasal, faríngea, laríngea, esofagiana, labial, vaginal, cervical, uretral e anal. ${ }^{46,47}$ Cunha et al. descreveram o caso de uma paciente de PV com envolvimento do cérvix uterino, tratada com sucesso com talidomida $(100 \mathrm{mg} / \mathrm{dia})$, que não havia respondido a tratamentos convencionais anteriores (Figura 6). ${ }^{48}$

Pênfigo vegetante é rara variante do PV (um a $2 \%$ dos casos), em que lesões vegetantes túmidas ocorrem especificamente em áreas intertriginosas. ${ }^{49,50}$ No curso inicial, as lesões são similares às do PV; no curso tardio, todavia, elas se tornam
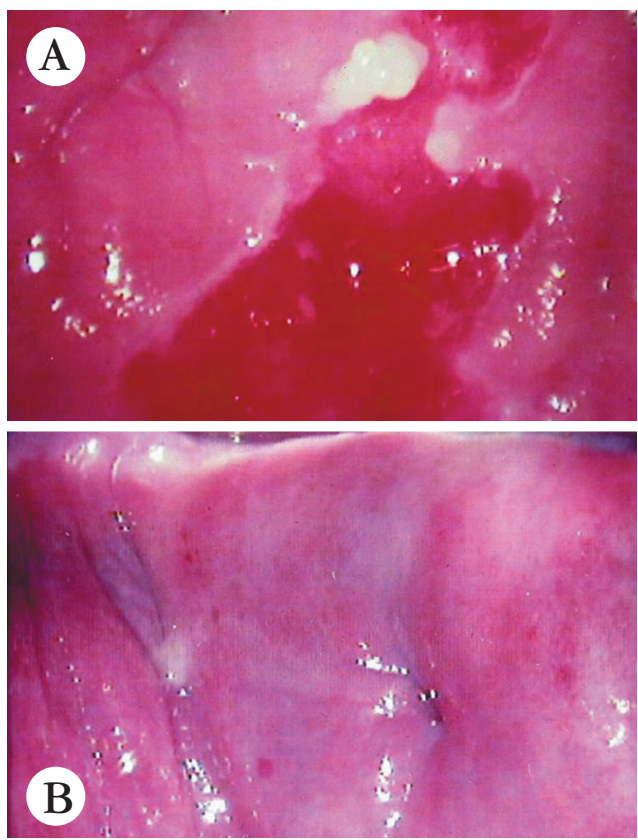

Figura 6: Pênfigo vulgar. A lesão no cérvix uterino. B. Após tratamento talidomida hipertróficas, vegetantes e verrucosas, particularmente nas áreas intertriginosas (Figura 7). A histopatologia do pênfigo vegetante é similar à do PV, embora naquela forma haja papilomatose e acantólise, com ocasional formação de abscessos eosinofilicos intraepidermais. ${ }^{51} \mathrm{O}$ curso da doença é prolongado, com períodos de remissão e recidivas. Uma das complicações frequentes é a infecção bacteriana secundária do PV, e podem ocorrer desnutrição e caquexia.

\section{DIAGNÓSTICO LABORATORIAL Histopatologia}

A lesão é caracterizada pela formação de bolha intraepidérmica localizada na maioria dos casos, imediatamente acima da camada basal da epiderme (suprabasal). A localização da bolha do PV nessa área correlaciona-se bem com a distribuição da Dsg3 na epiderme, onde a Dsg3 tem sua maior expressão.

\section{Imunofluorescência}

Imunofluorescência direta (IFD) usando tecido perilesional mostra, em todos os casos com doença em atividade, depósitos de IgG e complemento na superfície dos queratinócitos em toda a epiderme. Em pacientes com lesões restritas à mucosa oral, a IFD de pele sadia, de nádegas, por exemplo, pode ser positiva, permitindo diagnóstico precoce. ${ }^{45}$

Imunofluorescência indireta (IFI), usando como substrato pele humana normal ou esôfago de macaco, demonstra anticorpos IgG circulantes na superfície das células dos queratinócitos. ${ }^{52} \mathrm{~A}$ sensibilidade da imunofluorescência é de $83 \%$ usando como substrato pele humana e de $90 \%$ com esôfago de macaco. $^{53}$

\section{Elisa (Enzyme-Linked Immunosorbent Assay)}

Os anticorpos circulantes IgG no PV podem ser detectados no teste de Elisa, usando Dsg1 e Dsg3 recombinantes. ${ }^{54}$ Encontra-se Dsg3 de $130 \mathrm{kD}$ no pênfigo vulgar mucoso e Dsg1 e Dsg3 (160kD e 130kD) no pênfigo vulgar mucocutâneo.

\section{DIAGNÓSTICO DIFERENCIAL}

Devem ser excluídas as demais formas de pênfigo e outras doenças bolhosas, tais como penfigóide bolhoso, penfigóide de membranas mucosas e epidermólise bolhosa adquirida.

\section{TRATAMENTO}

Antes do advento dos corticosteróides, a taxa de mortalidade variava entre 60 e $90 \% .{ }^{55}$ Atualmente, não obstante todas as novas modalidades terapêuticas, a doença ainda é grave, com taxa de mortalidade de $5 \%$. Muitos dos pacientes sucumbem pela compli- 


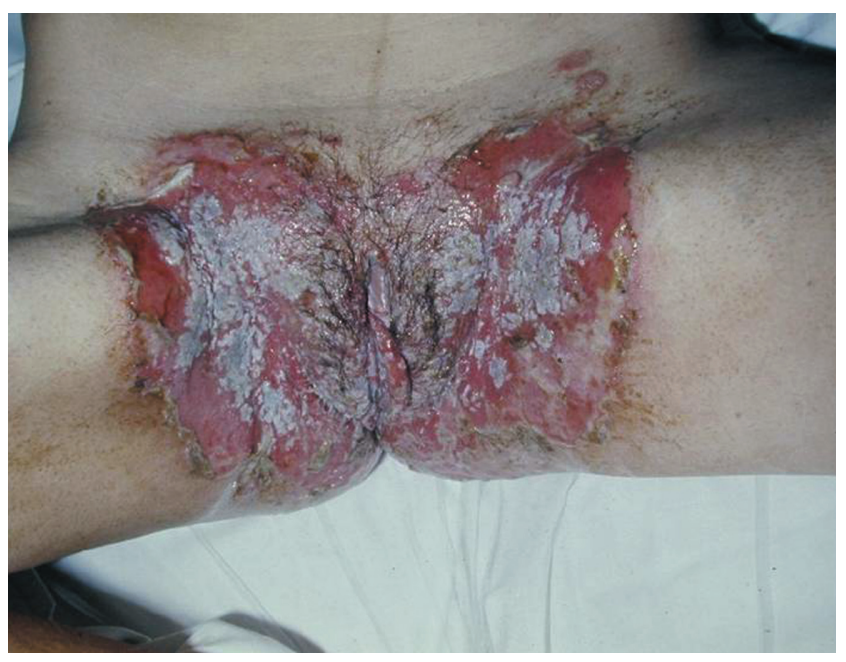

FiguRA 7: Pênfigo vegetante - erosões nas regiões genital e inguinocrural

cação dos tratamentos e não pela doença propriamente dita. O tratamento habitualmente indicado é prednisona na dose de $1-2 \mathrm{mg} / \mathrm{kg} / \mathrm{dia}$ de acordo com a gravidade da doença. Não havendo melhora com a corticoterapia isolada no período de uma semana, indicase a associação com medicação imunossupressora. A primeira indicação de imunossupressor é azatioprina na dose $2 \mathrm{mg} / \mathrm{kg} /$ dia. Como segunda opção utiliza-se micofenolato mofetil na dose de $35-45 \mathrm{mg} / \mathrm{kg} / \mathrm{dia}$. Doentes que não apresentam melhora significativa podem ser tratados com pulsoterapia com metilprednisolona na dose de $1 \mathrm{~g} /$ dia EV durante três dias consecutivos. ${ }^{6}$ Imunoglobulina endovenosa na dose total de $2 \mathrm{~g} / \mathrm{mês}$, dividida em cinco dias consecutivos, é outra opção para os casos de difícil tratamento e efetiva como terapia concomitante ou monoterapia. As aplicações mensais deverão ser mantidas até remissão clínica, depois aumentar os intervalos das infusões para seis, oito,10, 12 e 14 semanas, e suspender o tratamento após obtenção da remissão clínica com intervalo superior a 16 semanas. ${ }^{56,57}$ Há relatos recentes de tratamentos de casos graves resistentes a outras terapêuticas com Rituximab (anticorpo monoclonal quimérico antiCD20) na dose $375 \mathrm{mg} / \mathrm{m}^{2} \mathrm{EV}$ semanalmente, durante quatro semanas consecutivas. $O$ tratamento é bem tolerado, com relatos de remissão prolongada da doença com ciclo único de tratamento. Efeitos colaterais associados à infusão: náusea, febre, calafrios, urticária, prurido, hipotensão e cefaléia. ${ }^{58}$

Sulfona na dose de $100 \mathrm{mg} /$ dia pode ser indicada nos casos leves e principalmente para manter o paciente em remissão. A diminuição das doses de corticóides deve ser bastante lenta e iniciada após a completa cicatrização das lesões. É recomendável o tratamento para estrongiloidíase, mesmo com exame parasitológico de fezes negativo em pacientes com PV tratados com corticóide. Recomenda-se proteção solar aos portadores de PV, porque as lesões podem ser exacerbadas pela luz ultravioleta,$^{59}$ e lembra-se que a gravidez pode precipitar ou agravar $\mathrm{O} \mathbf{P V}^{60,61}$

Concluindo, o futuro próximo indica que o tratamento com biológicos poderá ser a terapêutica de primeira escolha no tratamento do PV grave, evitando assim o uso de altas doses de corticóides e terapias imunossupressoras.

\section{PENFIGÓIDE BOLHOSO}

O penfigóide bolhoso (PB) é doença autoimune, crônica, limitada, com formação de bolhas, principalmente em indivíduos idosos, de todas as raças. Alguns casos têm sido descritos na infância ${ }^{62}$ (Figura 8). Os casos ocorrem esporadicamente, e não há evidências de que exista um componente genético no desencadeamento da doença. ${ }^{63}$

Autoanticorpos da classe IgG são identificados e dirigem-se contra antígenos de $230 \mathrm{KD}$ e $180 \mathrm{KD}$, designados como BP 230 Ag1 e BP 180 Ag2, respectivamente. O BP 230 localiza-se na placa hemidesmossômica intracelular, e o BP 180 é glicoproteína transmembrânica, cujo domínio extracelular ultrapassa a lâmina lúcida da zona de membrana basal, ${ }^{6}$ (Figura 9).

\section{MANIFESTAÇÕES CLÍNICAS}

A doença é caracterizada clinicamente pela combinação de máculas eritematosas, pápulas, placas e vesículas, bolhas grandes, tensas e áreas de erosões. As lesões são generalizadas e podem afetar a pele das áreas flexurais e intertriginosas. As lesões das membranas mucosas (geralmente oral) ocorrem em 10 a $30 \%$ dos casos. ${ }^{6,63}$ As lesões são localizadas geralmente em superfície extensora dos membros, cabeça e pescoço. Na variedade eritematosa, predominam mácula e eritema. Há também a variante vesicular, com lesões clínicas e histopatológicas similares à dermatite herpetiforme. ${ }^{6,63}$
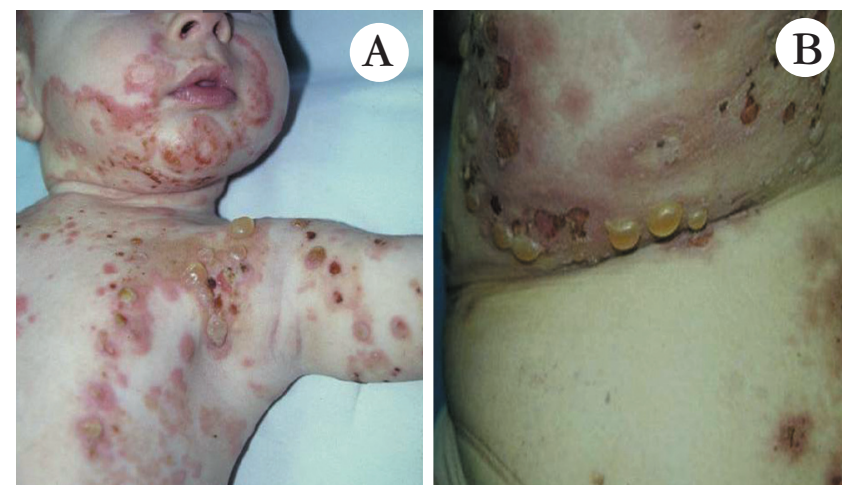

Figura 8: A. Penfigóide bolhoso - bolhas tensas de conteúdo claro sobre pele eritêmato-edematosa urticariforme. B. Penfigóide bolhoso em criança de dois meses de idade 


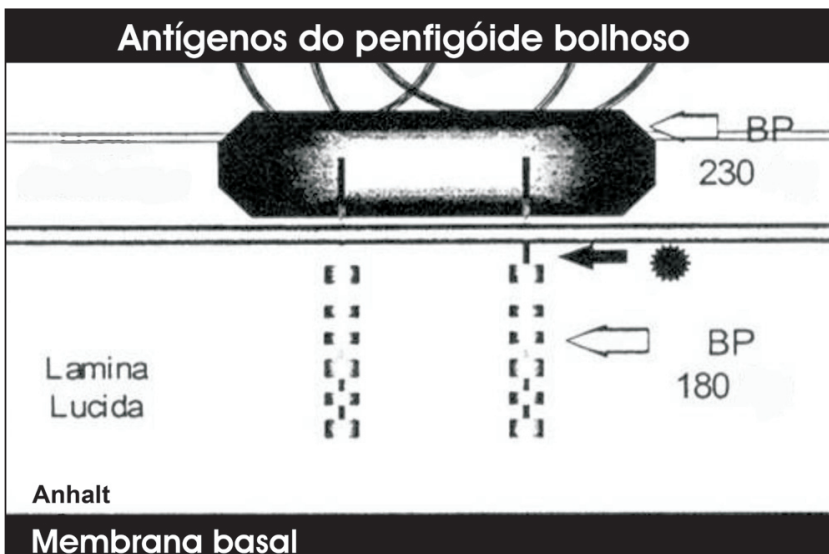

Figura 9: Antígenos do penfigóide bolhoso

Nos estádios recentes da doença pode haver manifestações inespecíficas com prurido intenso, escoriações e ausência de bolhas, fase inicial ou prébolhosa do PB, sendo extremamente difícil estabelecer o diagnóstico nessa fase. Hofmann et al. ${ }^{64}$ investigando a presença de anticorpos contra o antígeno BP180 e um grupo de pacientes idosos com prurido de causa desconhecida, demonstraram que 3/25 (12\%) apresentavam anticorpos contra o BP180, dado que poderia dar suporte à existência da fase prébolhosa do PB.

É descrita a associação do PB com neoplasia, entretanto há dúvidas se essa correlação é real, pois essas duas doenças ocorrem em faixa etária mais alta. O que se deve fazer é checar se existem ou não tumores nos portadores de penfigóide bolhoso. ${ }^{65}$

\section{HISTOPATOLOGIA}

A histopatologia do PB apresenta-se com bolha subepidérmica não acantolítica, epiderme intacta e inflamação dérmica. O infiltrado inflamatório é composto por linfócitos, histiócitos, sendo a presença de eosinófilos sugestiva da doença. ${ }^{66,67}$

\section{DIAGNÓSTICO}

O quadro clínico, a histopatologia e imunofluorescência direta e indireta indicam o diagnóstico.

$\mathrm{Na}$ imunofluorescência direta encontram-se depósitos de IgG e complemento na zona da membrana basal, com IgG em torno de 90 a 95\% dos casos e C3 em 100\% deles. Depósitos de IgG raramente estão presentes na ausência de C3, mas a presença de IgA, IgM e IgE tem sido descrita. ${ }^{66}$

$\mathrm{Na}$ imunofluorescência indireta encontra-se IgG, subclasse IgG4, importante para o diagnóstico diferencial do penfigóide bolhoso em relação a outras dermatoses, como por exemplo herpes gestacional, penfigóide cicatricial, epidermólise bolhosa adquirida, lúpus eritematoso sistêmico bolhoso, dermatite herpetiforme e dermatose por IgA linear. ${ }^{68}$

$\mathrm{Na}$ imunomicroscopia eletrônica, observam-se depósitos de IgG na lâmina lúcida e hemidesmossomo na zona da membrana basal (ZMB) ${ }^{69}$

Para diferenciar o penfigóide bolhoso da epidermólise bolhosa adquirida (EBA), utiliza-se, na imunofluorescência indireta, a técnica de separação dermoepidérmica com $\mathrm{NaCl}$ (split skin), na qual há fluorescência predominante no teto nos casos de $\mathrm{PB}$, enquanto na EBA ocorre no assoalho. ${ }^{69}$

$\mathrm{Na}$ atualidade já se dispõe comercialmente do teste de Elisa para detectar os anticorpos circulantes do PB, contra os antígenos BP180 e BP230. Trata-se de teste prático e de fácil execução, podendo ser útil para prever recidivas da doença após interrupção da terapia. ${ }^{70}$

\section{TRATAMENTO}

Nas formas localizadas, além dos cuidados locais com limpeza, podem-se usar corticóides tópicos. ${ }^{6,71}$ Nas formas tradicionais da doença, podemos utilizar o corticosteróide sistêmico, como a prednisona, na dose de $1 \mathrm{mg} / \mathrm{kg} /$ dia associado à dapsona, na dose de $100 \mathrm{mg} /$ dia. É preferível regredir o corticosteróide, mantendo a dapsona. ${ }^{6,71}$ Outros tratamentos podem ser utilizados, como a tetraciclina $2 \mathrm{~g}$ /dia associada à nicotinamida $1,5 \mathrm{~g} / \mathrm{dia}$, metotrexato $5 \mathrm{mg} / \mathrm{sema}$ na, azatioprina $2 \mathrm{mg} /$ dia, ciclofosfamida $2 \mathrm{mg}$ /dia, micofenolato mofetil 25 a $35 \mathrm{mg} / \mathrm{kg} /$ dia (até dose máxima de $3 \mathrm{~g} / \mathrm{dia}$ ), ciclosporina $3 \mathrm{mg} / \mathrm{kg} / \mathrm{dia}$, imunoglobulina endovenosa $2 \mathrm{mg} / \mathrm{kg} / \mathrm{mês}$ e plasmaferese. ${ }^{6,71} \mathrm{Tem}$ sido descrito o uso de rituximab no tratamento dos casos mais rebeldes. ${ }^{72}$

\section{DERMATITE HERPETIFORME (DERMATITE DE DUHRING)}

Dermatite herpetiforme (DH) é doença clinicamente caracterizada por lesões urticariformes e bolhas. Foi descrita em 1884, mas só em 1966 foi reportada a ocorrência de anormalidades na mucosa jejunal e, posteriormente, de depósito de IgA na derme papilar. ${ }^{6,73}$ É doença bolhosa crônica associada à enteropatia sensível ao glúten (doença celíaca), clínica ou subclínica em todos os casos. Há susceptibilidade genética para manifestação da doença, demonstrada pela associação entre dois HLA específicos, que são HLA-DQ2 e HLA-DQ8. ${ }^{6}$ Nessa doença, há presença de IgA de forma granular, grumosa, pontilhada ou fibrilar ao longo da zona da membrana basal (ZMB) e da derme papilar abaixo da ZMB na imunofluorescência direta. ${ }^{66,69}$ Afeta mais adultos, sendo mais frequente no sexo masculino. Evolui por surtos e não compromete o estado geral. Acomete indivíduos entre 30 e 40 anos de idade, sendo comum o acometimento de pacientes com doença celíaca. ${ }^{73}$ Embora a relação entre pele e intestino ainda não seja bem estabeleci- 
da, com dieta isenta de glúten as lesões melhoram sensivelmente. ${ }^{73,74}$

Para a maioria dos doentes, a enfermidade é crônica, com períodos de melhora.

\section{MANIFESTAÇÕES CLÍNICAS}

O doente apresenta-se com lesões papulovesiculosas que, quando se agrupam, formam aspecto herpetiforme. As lesões da DH são simetricamente distribuídas e se localizam sobretudo nas superfícies externas de cotovelos e joelhos, na fronte, região superior do dorso, região sacral e nádegas, regiões escapulares, podendo ocorrer em qualquer parte do corpo. As lesões podem apresentar-se escoriadas pelo prurido, que é uma característica da $\mathrm{DH}$ e pode ser muito intenso, em geral não se correlacionando com a extensão da doença clínica. As mucosas geralmente não estão comprometidas. ${ }^{6,73,74}$ Outros sinais podem acompanhar a DH, como anemia, osteopenia, osteoporose, alterações dentárias, infertilidade e aborto, e sua associação com outras doenças autoimunes é bastante comum.

\section{DIAGNÓSTICO}

A coleta de material para biópsia de lesão urticada deve ser feita próximo às bolhas, e o exame histopatológico mostra vesicobolha não acantolítica subepidérmica com infiltrado inflamatório neutrofílico (microabscessos) na derme papilar.

A imunofluorescência direta mostra depósitos de IgA de forma granular, fibrilar ou pontilhada, concentrada nas papilas dérmicas e ao longo da $\mathrm{ZMB},{ }^{69}$ importante para o diagnóstico diferencial com penfigóide bolhoso, que apresenta depósito linear de IgG e C3 ao longo da ZMB (Figura 10).

\section{A imunofluorescência indireta é negativa.}

Anticorpos séricos direcionados contra gliadina (um componente do glúten), endomísio (tecido conectivo ao redor de músculo liso) e transglutaminase tecidual estão presentes na doença glúten-sensível, devendo ser feitos testes sorológicos (IFI, Elisa) para esses autoanticorpos, a fim de monitorar a resposta
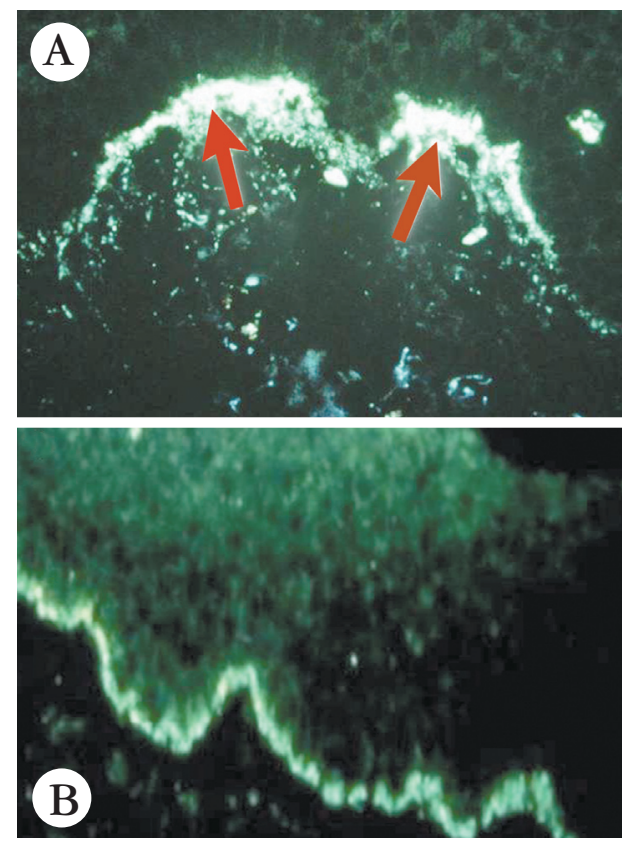

Figura 10: A.

Dermatite herpetiforme: imunofluorescência direta depósitos de IgA de forma granular nas papilas dérmicas ao longo da zona da membrana basal (ZMB). B. Penfigóide bolhoso: imunofluorescência direta com depósito linear ao longo da ZMB, de C3 e de IgG

terapêutica e a aceitação da dieta isenta de glúten., ${ }^{6,63,74}$ Anticorpos IgA contra transglutaminase tecidual (detectada por Elisa) atualmente são considerados diagnóstico sorológico marcador de $\mathrm{DH}$ e doença celíaca. A transglutaminase epidérmica é considerada o autoantígeno das lesões cutâneas na DH, e ocorrem reações cruzadas entre os anticorpos que reconhecem as transglutaminases epidérmica e intestinal.

Pacientes com DH e doença celíaca apresentam risco aumentado de desenvolver linfoma gastrointestinal, e dieta livre de glúten protege contra esse risco.

$\mathrm{Na}$ diagnose diferencial devem ser considerados os quadros de: penfigóide, dermatite por IgA linear, escoriações neuróticas, escabiose, eczemas, picadas de inseto e eritema polimorfo.

\section{TRATAMENTO DA DH}

A dieta deve incluir restrição rigorosa ao glúten e ao iodo, que podem desencadear a doença. Utilizase dapsona na dose de 100 a $400 \mathrm{mg} / \mathrm{dia}$, associada ou não à corticoterapia. Associa-se a riboflavina, na dose de $5 \mathrm{mg}$, duas vezes ao dia. ${ }^{74}$ 


\section{REFERÊNCIAS}

1. Paes Leme C. Contribuição ao estudo do Tokelau [tese]. Rio de Janeiro: Faculdade de Medicina do Rio de Janeiro; 1903.

2. Campos JA. Semana de combate ao "Fogo Selvagem". São Paulo: Revista dos Tribunais; 1939.

3. Campos JA. Pênfigo foliáceo (Fogo-Selvagem). Aspectos clínicos e epidemiológicos. São Paulo: Melhoramentos; 1942.

4. Proença NG. Declínio do pênfigo foliáceo no Estado de São Paulo (Brasil). Rev Paul Med. 1977;89:97-100.

5. Cunha PR. Estudo Soro-epidemiológico em foco de pênfigo foliáceo endêmico (fogo selvagem) no estado de São Paulo [tese]. São Paulo (SP): Universidade de São Paulo; 1988.

6. Sampaio SA, Rivitti EA. Dermatologia. 3a ed. São Paulo: Artes Médicas; 2007. p. 301-30.

7. Diaz LA, Sampaio SA, Rivitti EA. Endemic pemphigus foliaceus (Fogo Selvagem): II. Current and historic epidemiologic studies. J Invest Dermatol. 1989;92:4-12.

8. Campbell I, Reis V, Aoki V, Cunha PR, Hans Filho G, Alves G, et al. Pênfigo foliáceo endêmico / fogo selvagem. An Bras Dermatol. 2001;76:13-33.

9. Beutner EH, Prigenzi LS, Hale W, Leme Cde A, Bier OG. Immunofluorescent studies of autoantibodies to intercellular areas of epithelia in Brazilian pemphigus foliaceus. Proc Soc Exp Biol Med. 1964;117:505-10.

10. Roscoe JT, Diaz LA, Sampaio SA, Castro RM, Labib RS, Takahashi Y. Brazilian pemphigus foliaceus autoantibodies are pathogenic to Balb/c mice by passive transfer. J Invest Dermatol. 1985;85:538-41.

11. Rock B, Martins CR, Theofilopoulos AN, Balderas RS, Anhalt GJ, Labib RS. The pathogenic effect of IgG4 autoantibodies in endemic pemphigus foliaceus (fogoselvagem). N Engl J Med. 1989;1320:1463-9.

12. Warren SJ, Lin MS, Giudice GJ, Hoffmann RG, HansFilho G, Aoki V. The prevalence of antibodies against desmoglein 1 in endemic pemphigus foliaceus in Brazil. Cooperative Group on Fogo Selvagem Research. N Engl J Med 2000;343:23-30.

13. Takahashi MDF. Imunopatologia do pênfigo foliáceo sul-americano. Estudo por imunofluorescência indireta [tese]. São Paulo: Faculdade de Medicina da Universidade de São Paulo; 1981

14. Lin MS, Swartz SJ, Lopez A, Ding X, Fernandez-Vina MA, Stastny P, et al. Development and characterization of desmoglein-3 specific $T$ cells from patients with pemphigus vulgaris. J Clin Invest. 1997;99:31-40.

15. Santi CG, Sotto MN. Immunopathologic characterization of the tissue response in endemic pemphigus foliaceus (fogo selvagem). J Am Acad Dermatol. 2001;44:446-50.

16. Moraes ME, Fernandez-Vina M, Lazaro A, Diaz LA, Filho $\mathrm{GH}$, Friedman $\mathrm{H}$. An epitope in the third hypervariable region of the DRB1 gene is involved in the susceptibility to endemic pemphigus foliaceus (fogo selvagem) in three different Brazilian populations. Tissue Antigens. 1997;49:35-40.

17. Lombardi C, Borges PC, Chaul A. Environmental risk factors in endemic pemphigus foliaceus (fogo selvagem). J Invest Dermatol. 1992;98:847-50.

18. Barraviera SR. Pênfigo foliáceo endêmico. Avaliação nutricional e imunológica [tese]. São Paulo: Faculdade de Medicina de Botucatu - UNESP; 1990.

19. Tur E, Brenner S. The role of the water system as an exogenous factor in pemphigus. Int $\mathrm{J}$ Dermatol. 1997;36:810-6.

20. Diaz LA, Arteaga LA, Hilario-Vargas J, Valenzuela JG, Li $\mathrm{N}$, Warren S, et al. Anti-Desmoglein-1 Antibodies in Onchocerciasis, Leishmaniasis and Chagas Disease Suggest a Possible Etiological Link to Fogo Selvagem. J Invest Dermatol. 2004;123:1045-51.

21. Schafer S, Koch PJ, Franke WW. Identification of the ubiquitous human desmoglein, Dsg2, and the expression catalogue of the desmoglein subfamily of desmosomal cadherins. Exp Cell Res. 1994;211:391-9.

22. Mahoney MG, Wang Z, Rothenberger K, Koch PJ, Amagai M, Stanley JR. Explanations for the clinical and microscopic localization of lesions in pemphigus foliaceus and vulgaris. J Clin Invest. 1999;103:461-8.

23. Sotto MN, Shimizu SH, Costa JM, De Brito T. South American pemphigus foliaceus: electron microscopy and immunoelectron localization of bound immunoglobulin in the skin and oral mucosa. $\mathrm{Br} \mathrm{J}$ Dermatol. 1980;102:521-7.

24. van Joost $\mathrm{T}$, Cormane RH, Pondman KW. Direct immunofluorescent study of the skin on occurrence of complent in pemphigus. Br J Dermatol. 1972;87:466-74.

25. Matis WL, Anhalt GJ, Diaz LA, Rivitti EA, Martins CR, Berger RS. Calcium enhances the sensitivity of immunofluorescence for pemphigus antibodies. J Invest Dermatol. 1987;89:302-4.

26. Cunha PR. Estudo comparativo da sensibilidade dos testes de imunofluorescência indireta (IFI) e immunoblotting (IB) para a detecção de anticorpos intercelulares nas diferentes formas e fases evolutivas do fogo-selvagem: eficiência da IFI em 4 diferentes substratos epiteliais [tese]. São Paulo: Universidade de São Paulo; 1997.

27. Squiquera HL, Diaz LA, Sampaio SA, Rivitti EA, Martins CR, Cunha PR. Serologic abnormalities in patients with endemic pemphigus foliaceus (Fogo selvagem), their relatives, and normal donors from endemic and nonendemic areas of Brazil. J Invest Dermatol. 1988; 91: 189-91.

28. Cunha PR, Jiao D, Bystryn JC. Heterogeneity in intercellular antibodies in fogo selvagem. J Invest Dermatol. 1996; 106:813.

29. Cunha PR, Bystryn JC. Sensitivity of indirect immunofluorescence and immunoblotting for the detection of intercellular antibodies in endemic pemphigus foliaceus (fogo selvagem). Int J Dermatol 1999;38:41-5.

30. Cunha PR, Bystryn JC, Medeiros EP, de Oliveira JR. Sensitivity of indirect immunofluorescence and ELISA in detecting intercellular antibodies in endemic pemphigus foliaceus (Fogo Selvagem). Int J Dermatol. 2006; 45:914-8.

31. Hilario-Vargas J, Dasher DA, Li N et al. Prevalence of Anti-Desmoglein-3 Antibodies in Endemic Regions of Fogo Selvagem in Brazil. J Invest Dermatol. 2006;126:2044-8.

32. Korman N. Pemphigus. J Am Acad Dermatol. 1988;18:1219-38. 
33. Stanley JR. Pemphigus. In: Fitzpatrick TB, Eisen AZ, Wolff K, editors. Dermatology in general medicine. New York: Mc-Graw-Hill; 1993. p. 606-15.

34. Ahmed AR, Yunis EJ, Khatri K, Wagner R, Notani G, Awdeh Z, et al. Major histocompatibility complex haplotype studies in Ashkenazi Jewish patients with pemphigus vulgaris. Proc Natl Acad Sci USA. 1990;87:7658-62.

35. Sinha AA, Brautbar C, Szafer F, Friedmann A, Tzfoni E, Todd JA, et al. A newly characterized HLA DQ beta allele associated with pemphigus vulgaris. Science. 1988;239:1026-9.

36. Wucherpfennig KW, Yu B, Bhol K, Monos DS, Argyris E, Karr RW, et al. Structural basis for histocompatibility complex (MHC)-linked susceptibility to autoimmunity: charged residues of a single MHC binding pocket confer selective presentation of self-peptides in pemphigus vulgaris. Proc Natl Acad Sci USA. 1995;92:11935-9.

37. Müller S, Stanley JR. Pemphigus: pemphigus vulgaris and pemphigus foliaceus. In: Wojnarowska $\mathrm{F}$, Briggaman RA, editors. Management of blistering diseases. New York: Raven; 1990. p. 43-63.

38. Bjarnason B, Flosadottir E. Childhood, neonatal, and stillborn pemphigus vulgaris. Int J Dermatol. 1990; 38:680-8.

39. Artz L, Tappeiner J. Atlas der Haut- und Geschlechtskrankheiten. Berlin: Urban und Schwarzenberg; 1953.

40. Eyre RW, Stanley JR. Identification of Penfigus vulgaris antigen extracted from normal human epidermis and comparison with pemphigus foliaceus atingen. J Clin Invest. 1988;81:807-12.

41. Ishii K, Amagai M, Hall RP, Hashimoto T, Takayanagi A, Gamou S, et al. Characterization of autoantibodies in pemphigus using antigen-specific enzyme-linked immunosorbent assays with baculovirus-expressed recombinant desmogleins. J Immunol. 1997;159:2010-7.

42. Masayuki A. Autoimmunity against desmosomal cadherins in pemphigus. J Dermatol Sci. 1999;20:92-102.

43. Ding X, Aoki V, Mascaro JM Jr, Lopez-Swidderski A, Diaz LA, Fairley JA (1997) Mucosal and mucocutaneous (generalized) pemphigus vulgaris show distinct autoantibody profiles. J Invest Dermatol. 109:592-596.

44. Amagai M, Tsunoda K, Zillikens D, Nagai T, Nishikawa T. The clinical phenotype of pemphigus is defined by the anti-desmoglein autoantibody profile. J Am Acad Dermatol. 1999; 40:167-70.

45. Braun-Falco O, Plewig G, Wolff HH, Winkelmann RK. Dermatology. Berlim: Springer-Verlag; 1991;664-668.

46. Hale EK, Bystryn JC. Laryngead and nasal involvement in pemphigus vulgaris. J Am Acad Dermatol. 2001; 44:609-11.

47. Hodak E, Kremer I, David M, Hazaz B, Rothem A, Feuerman P, et al. Conjunctival involvement in pemphigus vulgaris: a clinical, histopathological and immunofluorescence study. Br J Dermatol. 1990;123:615-20.

48. Cunha PR, de Oliveira JR, Salles MJ, Jamora J, Bystryn JC. Pemphigus vulgaris with involvement of the cervix treated using thalidomide therapy. Int J Dermatol. 2004:43:682-4.

49. Ahmed AR, Blose DA. Pemphigus vegetans: Neumann
Type and Hallopeau type. Int J Dermatol. 1984;23:135-141.

50. Jansen T, Messer G, Meurer M, Plewing G. Pemphigus vegetants: eine historische Betrachtung. Hautarzt. 2001;52:504-9.

51. Lever WF, Schaumburg-Lever G. Histopathology of the skin. Philadelphia: Lippincott; 1975.

52. Director W. Pemphigus vulgaris. A clinicopathological study. Arch Dermatol. 1952;65:155-69.

53. Harman KE, Gratian MJ, Bhogla BS, Challacombe Black MM. The use of two substrates to improve the sensitivity of indirect immunofluorescence in the diagnosis of pemphigus. Br J Dermatol. 2000;142:1135-9.

54. Amagai M, Komai A, Hashimoto T, Shirakata Y, Hashimoto K, Yamada T, et al. Usefulness of enzymelinked immunosorbent assay (ELISA) using recombinant desmoglein 1 and 3 for serodiagnosis of pemphigus. Br J Dermatol. 1999; 140:351-7.

55. Lever WF, Schaumburg-Lever G. Immunosuppressants and prednisone in pemphigus vulgaris. Therapeutic results obtained on 63 patients between 1961 and 1975. Arch Dermatol. 1977;113:1236-41.

56. Engineer L, Bhol KC, Ahmed AR. Analysis of current data on the use of intravenous immunoglobulins in management of pemphigus vulgaris. J Am Acad Dermatol. 2000;43:1049-57.

57. Ahmed AR, Dahi MV. Consensus statement on the use of intravenous immunoglobulin therapy in the treatment of autoimmune mucocutaneous blistering diseases. Arch Dermatol. 2003;139:1051-1059.

58. Arin MJ, Hunzelmann N. Anti-B-cell directed immunotherapy (rituximab) in the treatment of refractory pemphigus: an update. Eur J Dermatol. 2005;15:224-30.

59. Ruocco V, Pisana M. Induced pemphigus. Arch Dermatol Res. 1982;274:123-140.

60. Fainaru O, Mashiach R, Kupferminc M, Shenav M, Pauzner D, Lessing JV. Pemphigus vulgaris in pregnancy: a case report and review literature. Hum Reprod. 2000;15:1195-7.

61. Goldberg SN, Defeo C, Kirshenbaum N. Pemphigus vulgaris and preganancy: risk factors and recommendation. J Am Acad Dermatol. 1993;28:877-9.

62. Cunha PR, Thomazelsky PV, Hipólito E, Michalany NS, Bystryn JC. Bullous pemphigoid in a 2-months-old infant. Int J Dermatol. 1998;37:935-48.

63. Gammon WR. The immunopathology of bullous pemphigoid antibodies. In: Beutner EH, Chorzelsky TP, Kumar V. Immunopathology of the skin. New York: Wiley Medical; 1987. p. 323-36.

64. Hofmann SC, Tamm F, Hertl M, Borradori L. Diagnosis value of an enzyme-linked immunosorbent assay using BP180 recombinant proteins in elderly patients with pruritic skin disordes. Br J Dermatol. 2003;149:885-917.

65. Stone SP, Schoerer AL. Bullous pemphigoid and associated malignant neoplasms. Arch Dermatol. 1975;111:991-4.

66. Wu H, Schapiro B, Harrish TJ. Noninfectious vesiculobulloses and vesiculopustular disease. In: Elder DE, Elenitsas R, Johnson BL, Murphy GF. Lever's histopatology of the skin. 9th ed. Philadelphia: Lippincott Willians e Wilkins; 2005. p.241-91.

67. Barradoni L, Bernard F. Pemphigoid group. In: 
Bolognia JL, Jorizzo JL, Ronald RP. Dermatology Edinburgh: Mosby; 2003. p. 463-70.

68. Lamb PM, Patton T, Deng IS. The predominance of IgG4 in prodomal bullous pemphigoid. Int $\mathrm{J}$ Dermatol. 2008; $47: 150-3$.

69. Ichara VK, Rajalakslmi T. Direct immunofluorescence in cutaneous vesicobulloses lesions. Ind $\mathrm{J}$ Pathol Microbiol. 2007;50:730-2.

70. Di Zenzo G, Thoma-Uszynski S, Fontao L, Calabresi V, Hofmann SC, Hellmark T, Sebbag N, Pedicelli C, Sera F, et al. Multicenter prospective study of the humoral autoimmune response in bullous pemphigoid. Clin Immunol. 2008;128:415-26.

71. Lopes-Jornet P, Bermijo-Fenoll A. Treatment of pemphigus and pemphigoids. Med Oral Patol Oral Cir Bucal. 2005;10:410-1.

72. Schimidt E, Seitz CS, Benoit S, Brocker EB, Goebler M. Rituximab in autoimmune bullous diseases: mixed responses and adverse effects. $\mathrm{Br} \mathrm{J}$ Dermatol. 2007; 156:352-6.
73. Herron MD, Zone JJ. Dermatitis herpetiformis and linear IgA bullous dermatosis. In: Bolognia JL, JorizzoJL, Rapinni RP. Dermatology. Edinburgh: Mosby; 2007. p. 479-84.

74. Barraviera SRCS, Barraviera B, Machado PEA, Habermann MC, Stolf HO, Gonzaga HFS. Uso da riboflavina no tratamento da hemólise pela sulfona em doente com dermatite herpetiforme de Durhing Brocq deficiente em glutationa redutase. An Bras Dermatol. 1989;64:231-3.

ENDEREÇO PARA CORRESPONDÊNCIA / MAILING ADDRESS:

Paulo R. Cunba

Rua: Isaí Leiner, 152 -Jardim Brasil

13201854 Jundiaí SP

Tel./fax: (11) $4521-8459$

E-mail: drpaulocunba@bol.com.br

Como citar este artigo/ How to cite this article: Cunha PR, Barraviera SRCS. Dermatoses bolhosas autoimunes. An Bras Dermatol. 2009;84(2):111-24. 